
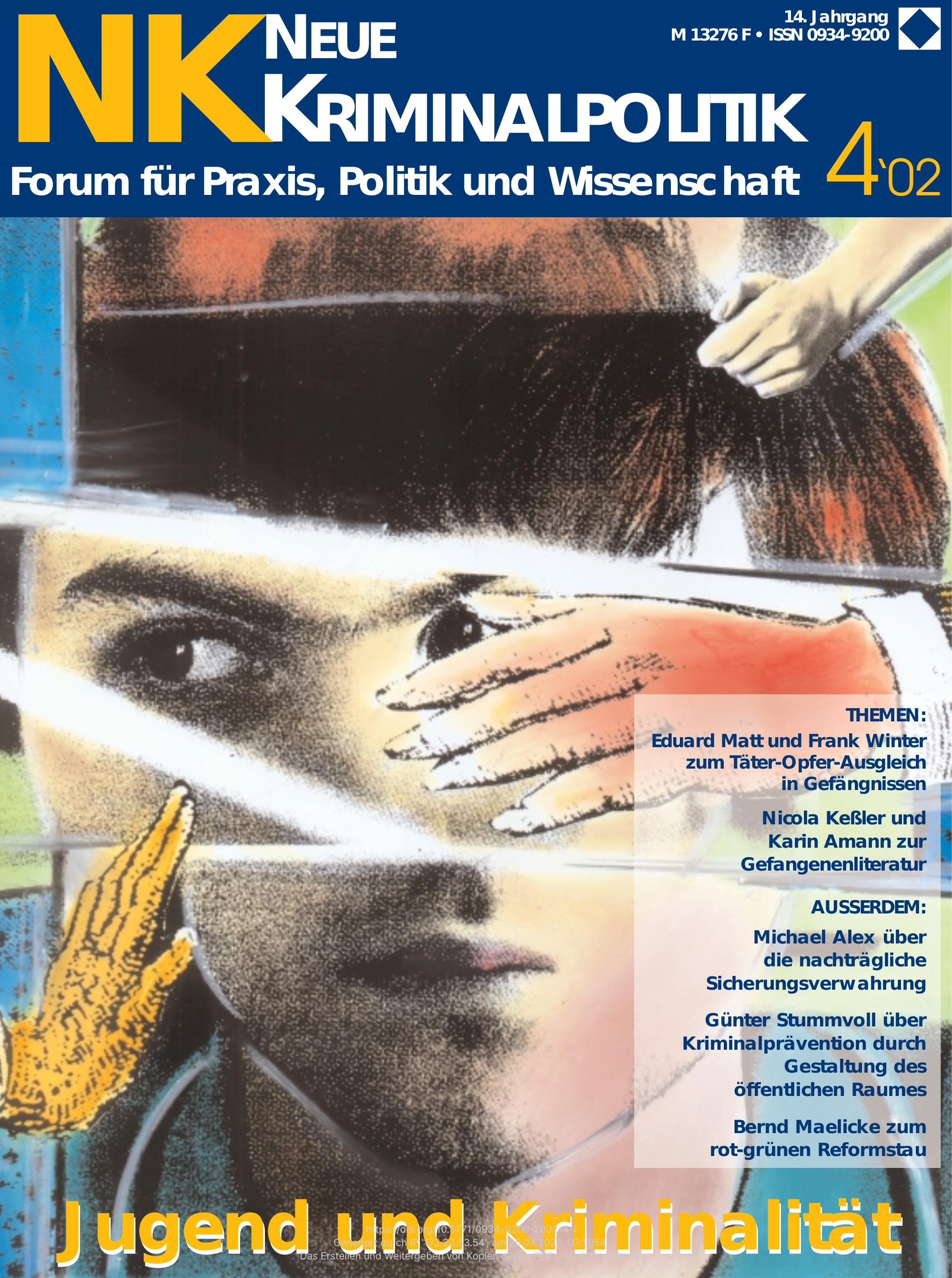


\section{NOMOS A ktuell}

\section{Festschrift für Klaus Rolinski}

Um den Regensburger Kriminologen Klaus Rolinski zu ehren, haben 30 renommierte $W$ issenschaftler aus den Bereichen Strafrecht, Strafprozessrecht und Kriminologie zu einer Festschrift beigetragen. Dabei haben sie Stellung genommen zu aktuellen Fragen ihrer jeweiligen Fachgebiete. Die Autoren zollen damit zugleich einem Verständnis der Kriminologie Tribut, welche gleichsam als kriminalpolitische und sozialwissenschaftlich empirische Disziplin die Strafrechtswissenschaften durchdringt. Auf diese Weise werden auch rechtliche Probleme mit entschiedener Praxisrelevanz innerhalb und außerhalb ihres dogmatischen Kontextes abgehandelt. So geht es in der strafrechtlichen Abteilung u.a. um Embryonenschut, Fahrtüchtigkeit und M ethadon-Substitution oder die G renzen des Steuergeheimnisses. In der strafprozessualen Abteilung finden sich Beiträge zum Verhältnis von Polizei und Strafprozessrecht, zum Zwischenverfahren oder zur Beweiswürdigung a us mathematischer Perspektive. Schließlich rundet der kriminologische Abschnitt, der von Kriminalprävention über Unrechtsbew usstsein bei Kindern, W irtschaftskriminalität und Dunkelfeldforschung bis hin zur viktimologischen Fragestellung reicht, den Band $a b$.

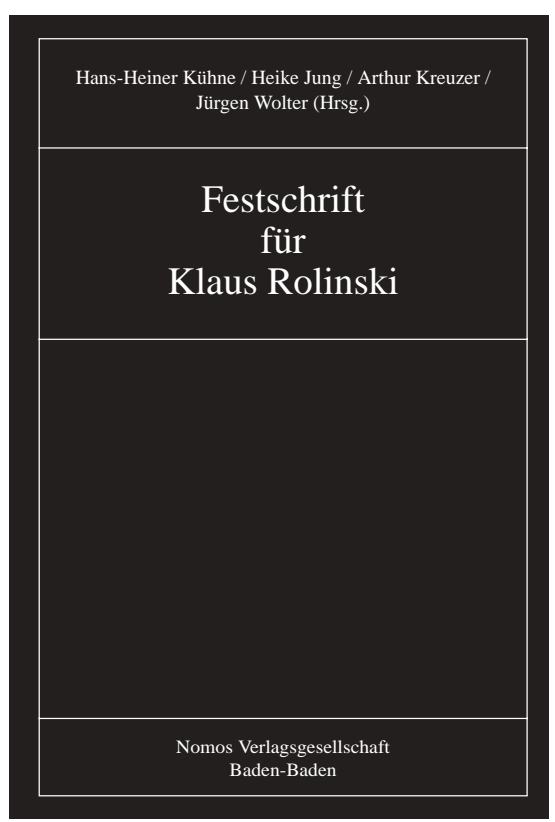

Hans-Heiner Kühne/ Heike Jung/ Arthur Kreuzer/ Jürgen W olter (Hrsg.)

Festschrift für Klaus Rolinski

2002, XIV, 507 S., geb.,

$128,-€, 217,-\mathrm{sFr}$,

ISBN 3-7890-8036-5 


\section{Reformen? Fehlanzeigel}

Nach Redaktionsschluss erreichte uns der neue Koalitionsvertrag aus Berlin, und wie Bernd Maelicke in seinem »Standpunkt « (Seite 127) bereits ahnt, findet sich darin kein Wort zu dringend gebotenen Reformen in der Kriminalpolitik. Dem ohnehin schmalen Abschnitt zur Innen- und Rechtspolitik ist Absatz für Absatz anzumerken, dass er in Ermangelung einer amtierenden Justizministerin unter der Federführung des Innenministers formuliert wurde. Kein Wort zum Thema Reform des Sanktionenrechts. Kein Wort zu den Themen Untersuchungshaft, Jugend-

strafvollzug (mit dieser Problematik befaßt sich der Beitrag von Bernd-Rüdeger Sonnen auf Seite 154 in diesem Heft) oder Ersatzfreiheitsstrafen. Kein Wort zu einer liberalen Drogenpolitik. Dafür reihenweise Stehsätze zur Kontrolle von Zuwanderung, über die vielfältigen Aufgaben der Geheimdienste und eine auslegungsbedürftige Passage zur neuen Kronzeugenregelung. Auf die aus dem Innenministerium kommende, rechtspolitisch bisher wenig profilierte neue Bundesjustizministerin kommt eine schwere A ufgabe zu, wenn sie in ihrem Bereich etwas bewegen will. Freilich kann man den Mangel an klaren Koalitionsaussagen auch als Chance begreifen. Viel weniger als die Amtsvorgängerin kann man bezogen auf die Kriminalpolitik ohnehin nicht erreichen. Und es hätte ja auch schlimmer kommen können: Mit populistischen Forderungen nach Strafverschärfungen, wie sie unter der anderen möglichen Koalition zu erwarten gewesen wären, hält sich Rot-Grün vorerst zurück. Es bleibt viel Gestaltungsspielraum, der sich in der einen wie der anderen Richtung nutzen ließe. W ir dürfen gespannt sein.

W ie immer beste Fachl ektüre wünscht Ihnen

Oliver Brüchert

\section{Titel: Jugend und Kriminalität}

Es gehört fast zum guten Ton, eine Geschichte aus der eigenen Jugend parat zu haben, in der man »etwas angestellt« oder auch eine größere »Dummheit« begangen hat. Wer möchte schon als Langweiler gelten? Selbstredend hat man den jugendlichen Leichtsinn später abgelegt, möchte die so gemachten Erfahrungen jedoch nicht missen. Jacken »abziehen «, Graffiti sprühen, Rangeleien mit Gleichaltrigen, Hasch rauchen - ein Großteil der »Jugendkriminalität« bewegt sich in diesem Bereich alterstypischer Devianz. Neue Studien über jugendliche Lebensstile und Cliquen untermauern einerseits diesen Befund, nehmen aber auch die problematischen Fälle in den Blick, bei denen es zu schwereren Delikten kommt oder die Clique zur »Bande« wird. Das erfordert komplexere Erklärungsansätze als Benachteiligung, »Frust« oder »Männlichkeit«. Im Titelthema ab Seite 140.

\section{MAGAZIN}

Replik:

Ende der Zweispurigkeit des Strafrechts durch nachträgliche Sicherungsverwahrung?

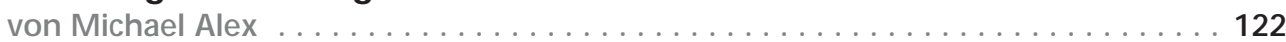

Kommunale Prävention:

Kriminalprävention durch Gestaltung des öffentlichen Raumes: CPTED

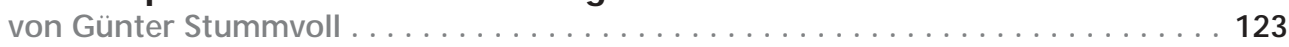

Standpunkt:

Neuer Aufbruch statt Reformstau?

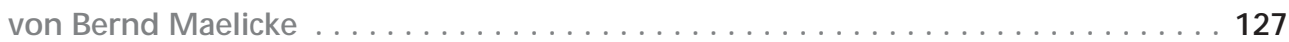

\section{THEMEN}

\section{Täter-Opfer-Ausgleich in Gefängnissen}

von Eduard Matt und Frank Winter . . . . . . . . . . . . . . . . . . . . . . . . . . . . . . . . . 128

Schreiben, um zu überleben

von Nicola Keßler und Karin Amann . . . . . . . . . . . . . . . . . . . . . . . . . . . . . . . . . . . 134

\section{TITEL}

\section{Jugend und Kriminalität}

von Klaus Boers . " 140

Wertorientierungen, Freizeitstile und Jugenddelinquenz

von Klaus Boers, Jost Reinecke, Katharina Motzke

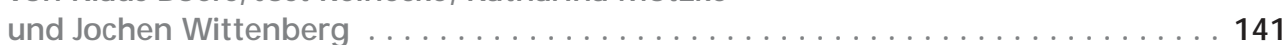

\section{Jugendliche in Cliquen}

von Thomas A. Wetzstein, Patricia Erbeldinger

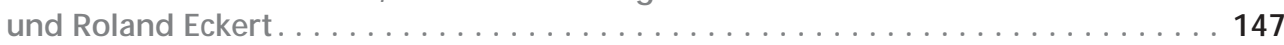

Thesen zum Thema »Männlichkeit« und Kriminalität

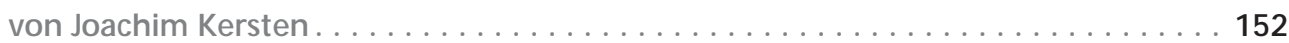

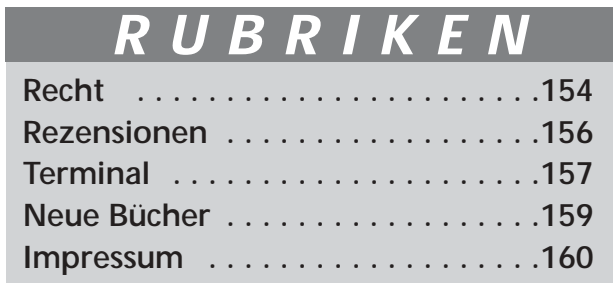

Kriminalsoziologische Bibliographie in der Heftmitte Beilagenhinweis:

Dieser Ausgabe liegt ein Prospekt der Nomos Verlagsgesellschaft bei. Wir bitten freundlichst um Beachtung. 